\title{
SER O NO SER... ESPAÑOL EN MÉXICO: LOS VAIVENES EN LA DEFINICIÓN Y ELECCIÓN DE LA NACIONALIDAD, $1821-1857^{*}$
}

Macrina Rabadán**

$\mathrm{P}_{\text {ocos son los conceptos que, como el }}$ de la nacionalidad, entrañan aspectos tan variados: desde el emotivo, expresado en el sentido de arraigo y pertenencia a cierto territorio, hasta cuestiones de derecho público y privado pasando por los ámbitos de la política interior y las relaciones internacionales. En países de reciente creación y descolonizados la definición de la nacionalidad plantea dificultades particulares, como la derivada de establecer el estatus y la relación de sus antiguos habitantes, procedentes de condiciones socioeconómicas distintas y, con frecuencia, recién enfrentados en una

* Gracias a la gentileza del Dr. Jaime del Arenal me fue posible consultar la legislación sobre el tema en la biblioteca de la Escuela Libre de Derecho (México, D. F.). La investigación en archivos españoles se hizo mediante una beca crédito del Consejo Nacional de Ciencia y Tecnología (CONACYT) para una estancia posdoctoral en España (octubre de 2000 a septiembre de 2001) y el apoyo de la Secretaría de Educación Pública, a través de su Programa para el Mejoramiento del Profesorado (PROMEP) para una breve estancia de investigación (julio de 2004). Agradezco a la Dra. Josefina Z. Vázquez sus observaciones a una primera versión de este texto, así como a los miembros del Seminario México-España de El Colegio de México, sus comentarios y sugerencias. Asimismo, recibí el auxilio oportuno y diverso de los doctores Aymer Granados y Raúl Figueroa Esquer, y de los maestros Alberto Segrera y Valentina Rabadán. Este artículo está dedicado a Begoña Pernas y Pedro Carreras.

** Universidad Autónoma del Estado de Morelos. 
contienda armada. Ése fue el caso respecto a los españoles americanos y peninsulares en México a partir de 1821, luego de las cruentas luchas desatadas en 1810, es decir, en las primeras décadas de su vida independiente y durante el tránsito de la Nueva España a la organización del nuevo Estado.

Los autores ${ }^{1}$ que han estudiado el tema de la nacionalidad ${ }^{2}$ mexicana en relación con la española en la primera mitad del siglo XIX, sobre todo a propósito de la problemática de la deuda externa mexicana, han afirmado su carácter 'ambiguo' o 'ambivalente', en términos de la legislación, para dar cuenta de la práctica de oscilar entre una y otra nacionalidades. Sin embargo, un acercamiento más estrecho tanto a las disposiciones legales como a la actividad diplomática y consular de la época nos permitiría advertir que detrás de esa aparente ambigüedad o indefinición en la legislación estaríamos más bien ante un juego de fuerzas e intereses, establecido entre los particulares (españoles y mexicanos), y las autoridades mexicanas y españolas. Lo anterior, en el contexto de un país con un Estado débil y severos problemas en su organización, como fue México en esa época, y donde la negociación cobraba un papel relevante, ya fuese para intentar modificar las leyes o bien para atenuar o neutralizar su efecto.

${ }^{1}$ Antonia Pi-Suñer, "Negocios y política a mediados del siglo XIX", en Clara Lida (comp.), Una inmigración privilegiada. Comerciantes, empresarios y profesionales españoles en los siglos XIX y XX, 1994, Madrid, Alianza Editorial, p. 75-96; Antonia Pi-Suñer y Agustín Sánchez, Una historia de encuentros y desencuentros. México y España en el siglo XIX, 2001, México, Secretaría de Relaciones Exteriores (en lo sucesivo, SRE); Rosa María Meyer, "Empresarios españoles después de la independencia", en Beatriz Rojas (coord.), El poder y el dinero. Grupos y regiones mexicanos en el siglo XIX, 1994, México, Instituto de Investigaciones José Ma. Luis Mora, p. 218-55; Rosa María Meyer, "El estilo empresarial de especular. Nacionalidad y finanzas a mediados del siglo XIX", en Rosa María Meyer y Delia Salazar (coords.), Los inmigrantes en el mundo de los negocios, 2003, México, Plaza y Valdés Editores, Consejo Nacional para la Cultura y las Artes (CONACULTA), Instituto Nacional de Antropología e Historia (INAH), p. 77-91.

${ }^{2}$ En las fuentes primarias decimonónicas es frecuente encontrar el uso indistinto de los términos 'nacionalidad' y 'ciudadanía' para referirse a la pertenencia a una nación. Sin embargo, en sentido más estricto, la ciudadanía nos remite más bien al ámbito de los derechos políticos. 
En este artículo me propongo abordar ese ir y venir entre las nacionalidades mexicana y española a partir de la correspondencia diplomática y consular, con especial atención a una fuente poco explorada hasta ahora: las solicitudes de 'cartas de seguridad'. ${ }^{3}$ Se trata de mostrar la no coincidencia entre lo que señalaba la legislación, por una parte, y lo que se registraba en la práctica en torno a la definición de la nacionalidad. Es decir, la frecuente aplicación discrecional de las leyes, lo que nos remite a la ausencia de un estado de derecho en el México de la primera mitad del siglo XIX. Las cartas de seguridad resultan útiles como fuente por haber sido documentos obligatorios para los extranjeros con los que acreditaban ese estatus y podían permanecer legalmente en el país. Dicho trámite daba lugar, asimismo, al registro de 'matrículas' en los consulados, donde quedaban asentados los españoles avecindados en el país. ${ }^{4} \mathrm{El}$ trabajo está dividido en dos partes: en la primera se tratarán las negociaciones entre las autoridades mexicanas y españolas en torno a la definición de la nacionalidad; en particular, los esfuerzos de los enviados hispanos encaminados a modificar, mediante convenios o por la sola presión diplomática, el marco legal mexicano para permitir que los españoles de origen, avecindados en México antes de 1821 y por lo tanto considerados mexicanos por las leyes de este país, recuperaran la nacionalidad española. En virtud de la obligación de los extranjeros -incluidos por supuesto los españoles- de contar con una 'carta de seguridad', cabría esperar

${ }^{3}$ Los datos contenidos en las cartas de seguridad eran el nombre, la nacionalidad y la media filiación del interesado. En este artículo no se trabajaron propiamente esas cartas, sino las solicitudes de los cónsules y vicecónsules adscritos en el interior del país, que hacían de intermediarios entre los particulares y el cónsul general en la ciudad de México, para que éste a su vez las tramitara en la secretaría de Relaciones Exteriores.

${ }^{4}$ Las matrículas a que tuve acceso corresponden al consulado general en la ciudad de México, en las que al parecer se concentraban las solicitudes de todo el país, y que contenían algunos de, o todos los siguientes datos: nombre, edad, lugar de residencia en México, año de llegada al país, año de nacimiento, lugar de origen, profesión, estado civil, número de carta de seguridad, fecha del registro y media filiación (color, estatura, pelo, ojos, nariz, barba y señas). (Un trabajo más detallado de estas matrículas será presentado próximamente.) Cabe mencionar que, por lo visto, sólo los hombres solicitaban carta de seguridad y por lo tanto quedaban registrados en las matrículas del consulado. 
que los logros obtenidos por los diplomáticos españoles y registrados en la legislación mexicana tendrían su contraparte en un aumento en el número de solicitudes de cartas de seguridad, realizadas a través de los consulados y viceconsulados españoles. Así, en la segunda parte se indagará sobre el impacto en la práctica de los convenios diplomáticos relativos a la nacionalidad, habida cuenta de que éstos proporcionaron a la población de origen peninsular cada vez mayores facilidades para elegir entre la nacionalidad mexicana y la española.

\section{La definición de la nacionalidad}

\section{A) El marco legal}

El Plan de Iguala y los Tratados de Córdoba constituyeron un primer llamado a la unidad de los antiguos combatientes, insurgentes y realistas, y mediante estos documentos quedaron definidos como mexicanos todos los habitantes del país que, sin importar su origen, permanecieran en él. ${ }^{5}$ La constitución de 1824 no identificó a los mexicanos ni a los extranjeros, sino que fiel a su espíritu federalista adjudicó a los estados la definición de ciudadanía. En las constituciones de éstos observamos que además de haber nacido en el estado, la mayoría de ellas establecieron la vecindad como una posibilidad para acceder a la naturaleza y ciudadanía. Con un espíritu de integración, varias de ellas reconocieron como naturales de los estados en cuestión a los 'extranjeros' que para 1821 se encontrasen avecindados en el país, en una velada referencia a los españoles peninsulares. ${ }^{6}$ Posteriormente, tanto la Constitución de 1836 o de las Siete Leyes, como las Bases de la Organización Política de la República Mexicana de 1843 estable-

5 "Plan de Iguala", 24 de febrero de 1821 y "Tratados de Córdoba", 24 de agosto de 1821, en Álvaro Matute (comp.), México en el siglo XIX. Antología de fuentes e interpretaciones históricas, 1984, México, Universidad Nacional Autónoma de México (UNAM), 4ª ed., p. 228 y 233 .

${ }^{6}$ Esta precisión me la hizo notar la doctora Josefina Z. Vázquez. 
cieron que los antiguos españoles peninsulares que habían llegado a la Nueva España antes de 1821 y permanecido en México más allá de esa fecha habían pasado a ser mexicanos, mientras que los españoles que llegaran después serían considerados extranjeros, a menos que solicitaran y obtuvieran carta de naturalización. A diferencia de sus predecesoras, la constitución de 1857 sí precisó quiénes eran mexicanos y quiénes extranjeros.

\section{B) El reconocimiento de España}

Luego de un largo período de quince años tras la declaración de Independencia de México en 1821 y de la reticencia del gobierno español a aceptar la existencia del nuevo Estado, la ex-metrópoli inició el esperado reconocimiento a las repúblicas hispanoamericanas en diciembre de 1836, ${ }^{7}$ seguido de la firma de un Tratado de Paz y Amistad (28 de diciembre de 1836), concertado por José María Calatrava, en su condición de secretario de Estado del gobierno de Su Majestad Católica, y Miguel Santa María, como enviado extraordinario de la República Mexicana ante la corte española. El Tratado fue ratificado en el año siguiente, pero debido a los acontecimientos políticos en el escenario español -la Guerra Carlista desatada a la muerte de Fernando VII-, la llegada del primer ministro plenipotenciario, Ángel Calderón de la Barca, para presidir la legación española en México se retrasó hasta diciembre de 1839. En ese tiempo regía en este país la constitución de 1836.

La apertura de la legación española en México marcó no sólo el inicio de una etapa importante en las relaciones diplomáticas entre ambos países, sino también se convirtió en el conducto más eficaz para la atención de solicitudes y quejas de los particulares. Así, desde su llegada el ministro Calderón de la Barca se encontró frente a las

${ }^{7}$ Josefina Z. Vázquez, México y el Mundo. Historia de las relaciones exteriores, 1990, México, Senado de la República, t. II, p. 73-8. 
demandas de españoles de origen, legalmente mexicanos, deseosos de recuperar la nacionalidad española. Las quejas y peticiones en ese sentido lo llevaron a iniciar a partir de enero de 1840 negociaciones con las autoridades mexicanas, encaminadas a resolver esa cuestión a favor de los particulares. Pero también desde ese primer momento el diplomático español advirtió los riesgos de tal operación:

Bien sé sin embargo que no puede a cada paso verificarse sin graves inconvenientes este bautizo político, porque la ciudadanía se convertiría en un tráfico: pero por eso mismo juzgo necesario que habiendo cesado las mencionadas circunstancias extraordinarias y singulares, es llegado el caso de que se deje a los españoles residentes en México cualesquiera que sea la época de su venida, la opción de elegir libre y espontáneamente, y con pleno conocimiento de las obligaciones que contraen, y de los privilegios que adquieren, entre ésta o aquella patria, ahora que formando dos naciones soberanas distintas, no pueden pertenecer del mismo modo a entrambas. ${ }^{8}$

\section{C) El decreto de 1842}

Como parte de su tentativa para lograr un cambio en la definición de la nacionalidad, el enviado español Calderón de la Barca se entrevistó con el ministro de Relaciones Exteriores, Juan de Dios Cañedo, en febrero de 1840, pero sin lograr nada en concreto. Sin embargo, en ese encuentro quedaron claras las posturas de ambas partes y la certeza del ministro español sobre la estrategia a seguir: "si el festina lente es aplicable a los negocios políticos en ninguna parte con mejor éxito que aquí donde, opino que más ha de conseguir la paciencia y la perseverancia que la fuerza o la razón".

Un obstáculo notable era la ley contenida en la Constitución de 1836 que prohibía a los extranjeros la adquisición de bienes raíces,

${ }^{8}$ Copia de un oficio (de Ángel Calderón de la Barca) a Juan de Dios Cañedo, México, 27 de enero de 1840, AMAE (véase al final del trabajo el significado de las abreviaturas de los archivos), legajo H 1647. 
aspecto que Calderón, al informar al primer secretario de Estado en Madrid, identificaba en el origen de la negativa mexicana para acceder a un cambio en la legislación:

En suma, Excmo. Señor, lo que quieren es considerar a los ricos propietarios españoles como mexicanos; no para los honores y puestos; pues sólo para ocupar éstos exclusivamente han hecho la revolución, a pesar de los pobres indios un puñado de criollos, que como en otra no lejana colonia creen una usurpación el menor empleo que se da a un peninsular. Ciudadanos mexicanos quieren que sean para distribuirles las contribuciones extraordinarias de que estarían exentos con arreglo al tratado, si los reconociesen como españoles. (...)

La esencia de la cuestión, si es que yo la entiendo bien, está en que subsistiendo la ley constitucional invalidará el derecho de muchos españoles y les coartará la libertad en el usufructo de su propiedad; ya suscitándoles embarazos para heredar en casos de bienes amayorazgados ya obligándoles a deshacerse de sus fincas rústicas o urbanas, si no se naturalizan, a los bajos precios a que las han reducido y la escasez del numerario y la inseguridad pública. ${ }^{9}$

A pesar de la negativa inicial y rotunda por parte de las autoridades mexicanas respecto a las principales demandas de su contraparte española, el ministro Calderón iba logrando, mediante la negociación, algunas concesiones que nos remiten a una aplicación discrecional de las leyes, como la seguridad de que "en casos dudosos de herencia y posesión anterior" se atenderían sus "representaciones: por manera, que un mayorazgo, o cualquier otro Español que herede, no será obligado a vender; porque entonces no se considerará que adquiere, que es lo prohibido; sino que conserva". ${ }^{10}$ Otro ejemplo fue el permiso para que el capitán del 'Jasón', un franciscano que se había enfermado en Veracruz, permaneciese "en la República al frente de una casa

${ }^{9}$ A. Calderón de la Barca al primer secretario de Estado y del Despacho, México, 6 de febrero de 1840, AHN, sección: Estado, legajo 5867, despacho número 16.

${ }^{10}$ A. Calderón de la Barca al primer secretario de Estado, México, 29 de febrero de 1840, AHN, sección: Estado, legajo 5867, despacho número 22. 
de educación; no obstante que por ley está prohibida la entrada de eclesiásticos españoles". ${ }^{11}$

En el ámbito mexicano, la cuestión de la nacionalidad fue sometida al Consejo de Gobierno, cuya comisión diplomática estaba formada por Manuel Eduardo de Gorostiza y Lucas Alamán. Éstos emitieron un 'dictamen' en el que expusieron los argumentos que hacían inaceptable la solicitud española:

No es justa porque los españoles que juraron la independencia de México no sólo adquirieron por este hecho los derechos de Ciudadanos sino que también contrajeron las obligaciones de tales y se comprometieron a llamarlas indefinidamente en cambio o remuneración de los beneficios que empezaron a reportar desde luego y que siguieron reportando. (...) Así, cuando se quiere hoy que vuelvan aquéllos a ser españoles, se pretende tácitamente que México prescinda de todo cuanto tuvo de benéfica la medida para la República en la época en que se tomó al paso que dichos españoles se quedarían con todas las utilidades que ella les procuró, sin retribuir con nada ni haber contribuido con nada en su obsequio.

El asunto pasaba también por la legislación existente:

Pero hay más y es que para obtener un resultado tan lastimoso tendría todavía el congreso que rasgar uno de los artículos más terminantes de nuestras leyes fundamentales y que dejan en manos extranjeras la mayor parte quizás de nuestras fincas rústicas y urbanas.

El resultado sería entonces el de establecer una brecha entre mexicanos y españoles:

Y véase entonces cuál sería la condición excepcional en que colocaríamos con declaración tan absurda a los ciudadanos que fueron ciudadanos mexicanos en galardón de separarse de nosotros cuando únicamente

${ }^{11}$ A. Calderón de la Barca al primer secretario de Estado, México, 6 de febrero de 1840, AHN, sección: Estado, legajo 5867, despacho número 16. 
podríamos necesitar de ellos; tendrían sobre los demás extranjeros inclusos los españoles la ventaja de ser como mexicanos en todo aquello en que la ley quiso favorecer a éstos y tendrían sobre los naturales del país la de poder acogerse a la protección de una Potencia extraña en cualquier caso en que se les exigiera algún sacrificio o cuando, por efecto de las circunstancias sus intereses fuesen lastimados. Se crearía un imperio dentro de otro imperio, se abriría la puerta a idénticas pretensiones de todos cuantos tienen tratados con nosotros bajo el pie de la nación más favorecida. Sería en fin, con el tiempo, un semillero de odios y rivalidades que tarde o temprano nos acarrearían dificultades diplomáticas con esa misma España con quien nos hemos reconciliado hoy de tan buena fe y quien hoy también nos mira con cariño aún fraternal. ${ }^{12}$

El hecho es que efectivamente se plantearon reclamaciones por daños sufridos en revueltas, como el saqueo del 4 de diciembre de 1828 , en el contexto de las elecciones de ese año y la revuelta de La Acordada que le sucedió. Calderón de la Barca explicó a sus superiores en España su proceder respecto a esas peticiones, apelando a la prudencia de los quejosos, en un intento por atenuar la beligerancia de sus solicitudes. Por cierto, Calderón no cuestionó la legalidad del estatus como mexicanos de los inconformes y en su llamado a la prudencia hizo notar a los interesados que:

principiar mi misión despertando estos recuerdos ya apurando al ya demasiado ahogado gobierno lejos de favorecerles les perjudicaría, $1^{\circ}$, porque creerían que venía lleno de exigencias, y $2^{\circ}$, porque con la constitución en la mano, me podrían replicar victoriosamente que no eran españoles, sino mexicanos; en favor de quienes a mí no me incumbía reclamar. ${ }^{13}$

${ }^{12}$ Copia del "Dictamen del Consejo de Gobierno", firmado por Lucas Alamán y Manuel de Cortázar, México, 4 de marzo de 1840, AHN, sección: Estado, legajo 5867, n 65. También citado en Pi-Suñer y Sánchez, op. cit., p. 69.

${ }^{13}$ Ángel Calderón de la Barca al Primer Secretario del Despacho de Estado, México, 26 de junio de 1840, AMAE, legajo H 1647, despacho número 58. 
Más aún, el asunto fue sometido en España al Tribunal Supremo de Justicia, instancia que en noviembre de 1841 emitió un 'dictamen' dirigido al Regente del Reino, refiriéndose a la 'legalidad y conveniencia’ de la reclamación. Respecto a la segunda, se dieron por válidas las consideraciones del ministro Calderón en el sentido de mantener una posición prudente y esperar condiciones propicias para 'agitar' otra vez la cuestión, mientras que sobre la primera, se afirmó que:

La legalidad de la reclamación apenas puede sostenerse a vista de las leyes a la razón existentes en la República de México. En la primera de las varias que componen la Constitución de aquel Estado y su párrafo $5^{\circ}$, se reputan y declaran Mejicanos todos los no nacidos en su territorio, que estaban fijados en la República, cuando ésta declaró su independencia, juraron la acta de ella, y han continuado residiendo allí. Este artículo, que según dice el Plenipotenciario, parece se hizo expresamente para los españoles, ha servido de fundamento para la oposición que ha hecho a la reclamación el gobierno de México. Y a la verdad según él deben considerarse como mexicanos todos los españoles que reconocieron la independencia, y juraron el acta de ella, cualesquiera que fuesen las razones que allá en su interior tuvieron para hacerlo, fuese por temor en los unos de los atentados y atropellamientos de que se viesen amenazados por parte de los nacidos allí descendientes de Europeos, o fuese en otros por la esperanza que les daba el Tratado de Iguala de que iría a reinar en aquel Estado un Príncipe de la dinastía Real de la Península. ${ }^{14}$

Las gestiones siguieron pero no sería don Ángel, sino su sucesor, Pedro Pascual de Oliver, el que encontraría una coyuntura favorable a sus expectativas, con la llegada a la presidencia de la República del general Antonio López de Santa Anna, ${ }^{15}$ pues se rumoraba que éste tenía "miras ulteriores sobre los bienes del clero, que no podrían en

14 "El Tribunal Supremo de Justicia (...) hace presente su dictamen”, Madrid, 17 de noviembre de 1841, AHN, sección: Estado, legajo 5867, nº 165.

${ }^{15}$ Los detalles de las negociaciones entre el representante español, Pedro Pascual de Oliver, y el Ministro de Relaciones Exteriores y Gobernación, José María de Bocanegra, se encuentran en AHN, sección Estado, legajo 5867, nº 174 al 177. 
su caso enajenarse sin la concurrencia extranjera". ${ }^{16} \mathrm{Al}$ parecer, Santa Anna decidió recompensar a un grupo de comerciantes extranjeros por su apoyo en la conspiración que él y Mariano Paredes tramaron para derrocar al presidente Anastasio Bustamante en 1841, ${ }^{17}$ con un decreto (11 de marzo de 1842) por el cual se permitía a los extranjeros la posesión de bienes raíces ${ }^{18}$ y que precedió al relativo al cambio de nacionalidad, emitido el 10 de agosto de ese mismo año. ${ }^{19}$ De acuerdo con este último, los españoles de origen que optaran por recuperar su antigua nacionalidad quedarían sujetos a las leyes de extranjería-como la obligación de proveerse de cartas de seguridad- y tenían un plazo de seis meses para realizar el trámite respectivo:

Antonio López de Santa Anna, con base en las facultades que le otorga la séptima de las bases de Tacubaya, juradas por los representantes de los departamentos, decreta que: Art. $1^{\circ}$ Los españoles que residían en la república al declararse la independencia nacional el año de 1821, y que hayan inscrito sus nombres en los registros que se mandaron abrir en los departamentos por circular de 25 de octubre último, expedida por el ministro de relaciones exteriores y gobernación, quedan en libertad de

${ }^{16}$ Pedro Pascual de Oliver al Primer Secretario del Despacho de Estado, México, 26 de octubre de 1841, número 14, docto. 92, en Relaciones Diplomáticas Hispano-Mexicanas (1839-1898), 1966, Despachos Generales I, 1844-1846, Serie I, t. III, (Prólogo de Luis Nicolau D’Olwer; selección y notas de Javier Malagón B., Enriqueta Lópezlira y José Ma. Miguel I V.), p. 271-4.

${ }^{17}$ Vázquez, op. cit., pp. 167-170 y Josefina Z. Vázquez, "El General Paredes y Arrillaga y los pronunciamientos de Guadalajara en 1841 y 1844”, en José María Muriá (Ed.), La Academia Mexicana de la Historia en Guadalajara, 1994, México, El Colegio de Jalisco, H. Ayuntamiento de Guadalajara, p. 65-79.

18 "Decreto del gobierno. Permite a los extranjeros adquirir bienes raíces en la República", 11 de marzo de 1842, en Manuel Dublán y José María Lozano (comps.), Legislación Mexicana o Colección completa de las disposiciones legislativas expedidas desde la Independencia de la República, ordenada por (...), 1876, México, Imprenta del Comercio, t. IV, p. 130-2. También en Colección de los decretos y órdenes de interés común que dictó el gobierno provisional, en virtud de las Bases de Tacubaya, 1850, México, Imprenta de J. M. Lara, t. 1841-1842, p. 374-7.

${ }^{19}$ Este hecho no fue considerado por Antonia Pi-Suñer y Agustín Sánchez cuando hicieron el balance del decreto del 10 de agosto de 1842 sobre nacionalidad, Pi-Suñer y Sánchez, op. cit., p. 70. 
renunciar la calidad de ciudadanos mexicanos que les fue concedida por el plan de Iguala y los tratados de Córdoba. $2^{\circ}$ Los españoles que renunciaren esa prerrogativa, usando de la libertad que les concede el artículo anterior, quedan desde ese actos sujetos en todo a las leyes vigentes de extranjería. $3^{\circ}$ Los españoles por nacimiento que hubiesen disfrutado de la cualidad de mexicanos desde el año de 1821 hasta ahora, continuarán considerados como corresponde a los que la gozan, si no la hubieren renunciado a los seis meses de expedido este decreto. ${ }^{20}$

Al comunicar a sus superiores las condiciones favorables para los españoles de ese decreto, Pedro Pascual de Oliver subrayó su validez y definitividad, en virtud del poder prácticamente ilimitado de Santa Anna en ese momento y de que incluso en el caso de que el nuevo congreso revisase los actos de ese gobierno, "lo cual es dudoso para muchos, hay ciertas medidas que como ésta no son fáciles de hacer por su carácter internacional". ${ }^{21}$ En otras palabras, el ministro había capitalizado muy bien la situación del momento.

\section{D) La prohibición del comercio al menudeo}

Una vez removido el obstáculo para la adquisición de bienes raíces, vendría una nueva disposición legal, de corte económico, que afectaba la cuestión de la nacionalidad: la prohibición para los extranjeros

${ }^{20}$ Colección de los decretos, y órdenes, t. II, 1842-1843, p. 40. También en Luis Miguel Díaz y Jaime G. Martini (comps.), Relaciones diplomáticas México-España (1821-1977), 1977, México, Porrúa, p. 140.

${ }^{21}$ Pedro Pascual de Oliver al primer secretario del Despacho de Estado, México, 28 de agosto de 1842, AHN, sección: Estado, legajo 5867, Exp. 174, despacho número 137. El representante español reportó el panorama político así: "El General Santa Anna está autorizado por las bases de Tacubaya, que son hoy el único pacto social que existe en la Nación, para organizar todos los ramos de la administración pública. Su poder no reconoce en la actualidad más límites que los de respetar la independencia del poder judicial; es en el hecho un Dictador cuyos actos están sin embargo sujetos a la aprobación del primer Congreso Constitucional, pero la constitución en virtud de la cual éste ha de reunirse no existe aún, ni ha empezado a ser discutida por el Congreso Constituyente que se instaló el 10 de junio último para este objeto." 
de practicar el comercio al menudeo, en virtud del decreto del 23 de septiembre de $1843 .{ }^{22}$ Éste preveía, sin embargo, tres posibilidades de exención: naturalizarse mexicano, el estar casado con mexicana o bien residir en la República con sus familias. Aunque las protestas de los enviados británico, norteamericano, prusiano, francés y español no se hicieron esperar, resultaban en última instancia los comerciantes franceses y españoles los más afectados por la medida, pues los de las otras nacionalidades se concentraban sobre todo en los grandes almacenes.

¿Qué tan perjudicial en la práctica resultó para los españoles una disposición tan aparentemente agresiva? ¿Cuántos de ellos recurrieron al cambio de nacionalidad con tal de conservar sus negocios? Desde luego estas preocupaciones se manifestaron en las autoridades en Madrid, que pronto pidieron informes al respecto. Sus representantes en México contestaron que se trataba de un dato difícil de obtener debido a que la naturalización era un trámite que se hacía directamente en las instancias mexicanas, pero aunque se advertía el efecto limitado de la ley, se reconocía también el riesgo del cambio de nacionalidad de los afectados con el fin de evitar el cierre de sus negocios:

Por dicha copia observará V.E. la imposibilidad que existe de adquirir dicho dato, así como el de los súbditos de S.M., que han abrazado la ciudadanía mexicana, para poder continuar con sus giros; pero por las noticias extrajudiciales que tengo, y por el número de certificados de excepción que he pedido, infiero que serán pocos los que tendrán que lamentar la pérdida de sus intereses con motivo de esta medida, aunque a muchos les habrá sido sensible renunciar a su nacionalidad; debiendo advertir a V.E., que deseoso yo de evitar en cuanto fuese posible que se lanzasen a este extremo, he facilitado con amplitud los certificados que exige el artículo 2o., de la ley de 23 de septiembre, para acreditar la pertenencia de los capitales. ${ }^{23}$

22 "Decreto del gobierno.- Prohibición a los extranjeros del comercio al menudeo", 23 de septiembre de 1843, en Dublán y Lozano, op. cit., t. 4, p. 571-2.

${ }^{23}$ Pedro Pascual de Oliver al Primer Secretario del Despacho, México, 23 de abril de 1844, AMAE, TR 441, despacho número 380. 
A través de una nota del secretario José Ma. Bocanegra al representante mexicano acreditado en Madrid conocemos el escaso número de comerciantes españoles que para marzo de 1844 habían solicitado y obtenido exenciones, sin especificar bajo qué modalidad: se trataba de 154 españoles, con la aclaración en el sentido de que "no pasan de catorce las tiendas cerradas en esta Capital pertenecientes a toda clase de extranjeros, de que pueda inferirse cuán corto será el número de las que lo hayan sido en las demás poblaciones de la República". ${ }^{24}$ Hacia finales del mes siguiente el ministro plenipotenciario español, Pedro Pascual de Oliver, remitía listas proporcionadas por Bocanegra con los nombres de los "españoles exceptuados de la prohibición del comercio al menudeo": 114 en total, así como de los "españoles naturalizados en la República desde el 23 de septiembre del año anterior hasta la fecha": 99. No obstante, en mayo de 1844 el cónsul de Veracruz daba cuenta de más de 120 españoles que habían optado por la naturalización a través del gobierno de ese Estado y, de paso, censuraba la conducta de sus paisanos. ${ }^{25}$

Las gestiones de Pedro Pascual de Oliver encaminadas a anular la prohibición del comercio al menudeo para los extranjeros fueron retomadas por su sucesor, Salvador Bermúdez de Castro, ${ }^{26}$ quien para 1845 informaba sobre el curso que había tomado esa cuestión: en una entrevista con el ministro de Relaciones, Luis Gonzaga Cuevas,

${ }^{24}$ Minuta. (El Secretario de Relaciones Exteriores de México) al ministro plenipotenciario en Madrid, (México), 30 de marzo de 1844, AHSRE, exp. 6-19-40, ff. 107-111.

${ }^{25}$ Telésforo G. de Escalante al primer secretario del Despacho de Estado (...), Veracruz, $1^{\circ}$ de mayo de 1844, AMAE, TR. 441, despacho número 2: "La fatal ley de 23 de septiembre último va produciendo sus efectos pues según me ha asegurado el gobernador del Estado más de ciento veinte españoles han pedido su naturalización tan sólo por su conducto./ Yo no me atrevo Excmo. Señor a calificar la conducta de estos españoles, pero sí puedo asegurar a V.E., que en su caso hubiera obrado de distinto modo."

${ }^{26}$ Para profundizar en los orígenes y trayectoria de este personaje véase Raúl Figueroa Esquer, Entre la intervención oculta y la neutralidad estricta. España ante la guerra entre México y Estados Unidos, 1845-1848, 1999, México, Instituto Tecnológico Autónomo de México (ITAM), SRE, p. 169-245. Algunos de los despachos referidos en el presente trabajo se encuentran también en Raúl Figueroa Esquer (comp.), España frente al México amenazado, 1845-1848, 2002, México, SRE. 
éste había cuestionado la validez de esa ley asegurándole que, al ser revisada por el Congreso, "sería declarada insubsistente en todas sus partes”. Ante esto, el diplomático español se apresuró a pugnar por la nulidad en los cambios de nacionalidad que esa disposición legal había propiciado:

Díjele entonces, que siendo insubsistente la medida en sí, debía serlo sin duda en sus efectos, y que esperaba por lo tanto no hallar cuando llegase el caso, obstáculo alguno para que se permitiese a los españoles, naturalizados mexicanos en virtud de la coacción que les impuso aquella ley, volver si lo tenían por conveniente bajo el pabellón de España. Quedose parado un momento, confesándome después, que no había mirado la cuestión bajo este punto de vista, ni preveía esta consecuencia, puesto que los españoles naturalizados Mexicanos no tenían ya derecho alguno a reclamar. Respondíle que era bien fácil preveer una consecuencia precisa y natural de una ley coactiva que iba a revocarse. ${ }^{27}$

Podemos advertir que ya se prefiguraba aquí lo que llegaría dos años más tarde, en 1847: un convenio que concedía las mayores facilidades para adquirir o recuperar la nacionalidad española. Por lo demás, el efecto de la prohibición de comerciar al menudeo quedó de hecho neutralizado en la práctica, incluso con el aval de las propias autoridades mexicanas, tal como lo informó Bermúdez de Castro a sus superiores:

El ministro de Relaciones Exteriores a quien continuamente hablo del asunto del menudeo me ha declarado que, mientras no revocan las Cámaras la ley de septiembre de 1843, él procederá respecto a los súbditos españoles como si tal ley no existiese, habilitando a cuantos deseen ocuparse del comercio al pormenor sin más formalidad que su solicitud, a cuyo efecto ha mandado terminantemente en su Secretaría, que se les den los permisos sólo con presentar su carta de ciudadanía española. ${ }^{28}$

${ }^{27}$ Salvador Bermúdez de Castro al primer secretario del Despacho de Estado, México, 29 de marzo de 1845, AMAE, TR 441, despacho número 3.

${ }^{28}$ Salvador Bermúdez de Castro al primer secretario del Despacho de Estado, México, 27 de noviembre de 1845, AMAE, TR 441, despacho número 157. 


\section{E) El convenio de 1847}

Las condiciones propicias para un nuevo arreglo diplomático sobre nacionalidad se presentó con la invasión norteamericana a México (1846-1848). Esta vez, el enviado Bermúdez de Castro reportó que las solicitudes procedían no sólo de españoles de origen, sino también de individuos que eran evidentemente mexicanos:

son tales y tan angustiosas las circunstancias de esta República, que muchos de sus más distinguidos personajes han venido reservadamente a suplicarme que los admita bajo el pabellón español. Otros, españoles de nacimiento, pero residentes en el país desde sus primeros años, arrepentidos de la pérdida de su ciudadanía, quisieran ampararse bajo su antigua bandera. Entre unos y otros cabalmente se halla lo más rico e ilustrado de la nación. (...)

En las continuas alarmas de estos últimos días, no sólo se me han presentado y me han escrito muchos españoles, sino que naturales de México, pertenecientes a todas las clases y condiciones, han venido a reclamar, como especial favor, la protección de nuestra bandera, pretendiendo renunciar solemnemente en mis manos la ciudadanía de la República. ${ }^{29}$

El diplomático español pidió instrucciones a las autoridades en Madrid para decidir cómo proceder ante esas peticiones y la respuesta se dio en el sentido de considerar que "toda la población mexicana que sea de origen español" podía ser "admitida bajo el pabellón español”, sin tener que recurrir al trámite de la naturalización. Según tan disparatada respuesta, esa regla general no se había podido cumplir totalmente en la práctica por no dejar despoblados a los nuevos Estados americanos. Es decir, que si el gobierno de México y sus leyes lo permitían, el español no pondría ningún obstáculo para favorecer la

${ }^{29}$ Salvador Bermúdez de Castro al primer secretario del Despacho de Estado, México, 23 de octubre de 1846, AHN, sección: Estado, legajo 5867, Exp. 220, despacho número 355, 'reservado'. 
vuelta a la nacionalidad española. Sin embargo, también se aconsejaba la prudencia ante el riesgo de que, al tratarse de los "ciudadanos más importantes de la República", surgiese "cierto resentimiento en aquel país contra la España y aun contra los mismos españolizados". ${ }^{30}$

En realidad, la solución a esas demandas llegó con un nuevo convenio sobre nacionalidad celebrado el $1^{\circ}$, de abril de 1847 , entre el enviado español, Salvador Bermúdez de Castro, y el ministro de Relaciones Exteriores, Manuel Baranda, mientras la presidencia de la República estaba a cargo de Antonio López de Santa Anna. El nuevo arreglo estipulaba las siguientes cláusulas:

1a. Todos los naturales de España llegados a la República antes o después del reconocimiento de su independencia y reputados como súbditos de la nación mexicana, quedan en completa libertad de volver a la ciudadanía española.

2a. Bastará el certificado del cónsul o vicecónsul de España en el distrito de su residencia y la autorización del representante de S.M.C., para que se les expidan las cartas respectivas de seguridad por el Ministerio de Relaciones Exteriores, no pudiendo adquirir de nuevo la ciudadanía mexicana sino en el modo y en los términos que establezcan las leyes generales de la República.

3a. Para todos los efectos políticos y civiles serán considerados en lo sucesivo como súbditos de S.M.C., del mismo modo que los que escogieron la ciudadanía de España en virtud del decreto de 10 de agosto de 1842. Los hijos seguirán la ciudadanía de sus padres hasta que, llegados a la mayor edad, elijan entre ésta y la del país de su naturaleza.

4a. Los que, en consecuencia de este arreglo, obtengan cartas de ciudadanos españoles, no podrán valerse del apoyo o intervención de la Legación de S.M.C., en los negocios que traigan su origen de la época en que disfrutaron los derechos de ciudadanos mexicanos. ${ }^{31}$

\footnotetext{
${ }^{30}$ Minuta. Al ministro plenipotenciario de S.M., en México, Madrid, 15 de junio de 1847 , AMAE, sección: Estado, legajo 5867, número 222.

${ }^{31}$ Salvador Bermúdez de Castro al primer secretario del Despacho de Estado, México, 28 de abril, 1847, despacho número 481, AMAE, TR. 441. Una copia de este convenio se encuentra también en AHSRE, exp. 7-15-47.
} 
Como era de esperarse, el convenio no cayó bien en el ámbito mexicano: recibió severas críticas en la prensa y el ministro Baranda, "acusado de traición por algunos diputados", fue llamado a la Asamblea a dar explicaciones sobre la cuestión. ${ }^{32}$ En cambio, su contraparte español se apresuró a subrayar las ventajas para España y sus súbditos, en términos de riqueza, influencia y poder, así como de las facilidades que representaba el acuerdo recién logrado:

En el beneficio concedido a los españoles no se establecen las excepciones ni se fija término: todos pueden volver en cualquier tiempo bajo el pabellón de España. La República renuncia a todos sus derechos de imperio y dominio sobre la parte más rica y más útil de su pueblo: los primeros capitales, las primeras fincas dejan de ser propiedades mexicanas. S. M. adquiere en este país un número considerable de súbditos, cuyas vastas posesiones, cuya notable riqueza les dan singulares medios de influjo y decidida preponderancia. México se debilita con lo que España se robustece. (...)

Este convenio es en el día el objeto de las conversaciones en México: conociéndose las resistencias constantes del gobierno y las dificultades del asunto, nadie creía posible tan completo resultado; y los españoles se sienten con orgullo fuertes y unidos otra vez, monopolizando de nuevo la preponderancia de un país que ha sido teatro por tantos años de sus padecimientos y divisiones. ${ }^{33}$

Años más tarde, el tono festivo del plenipotenciario español se vería cuestionado, a la luz de la experiencia, por los abusos a que dio lugar por parte de los particulares, poniendo en dificultades incluso a la propia legación española. Hacia finales de 1847, se suscitó todavía un pequeño debate en torno a la interpretación del artículo $3^{\circ}$, del convenio, es decir, sobre la nacionalidad de los hijos de españoles pero nacidos en México. Las instrucciones enviadas al encargado de

${ }^{32}$ Salvador Bermúdez de Castro al primer secretario del Despacho de Estado, México, 28 de mayo de 1847, AHN, sección: Estado, legajo no. 5867, Exp. 228, despacho número 493.

${ }^{33}$ Salvador Bermúdez de Castro al primer secretario del Despacho de Estado, México, 28 de abril de 1847, AMAE, TR 441, despacho número 481. 
negocios interino, Ramón Lozano, estipulaban considerar mexicanos a "los individuos nacidos en la República, cuyos padres, aunque fuesen nacidos en España, hubiesen muerto bajo la nacionalidad mexicana". ${ }^{34}$

En 1855 el ministro Lozano señalaba los efectos perniciosos del convenio de 1847 por no haber establecido un límite de tiempo para solicitar la nacionalidad española, pues en lo concerniente a las otras repúblicas hispanoamericanas el plazo máximo había sido de dos años. Para Lozano ocho años habían sido suficientes en el caso mexicano para que los interesados "pudieran optar entre una u otra nacionalidad, y a los españoles que por morosidad, conveniencia propia o escaso patriotismo" no lo habían hecho, era más recomendable retirarles ese derecho, pues de lo contrario se daba lugar a una "especie de especulación indigna, que no se halla el gobierno de S.M., en el caso de patrocinar". El ministro español había advertido los abusos por parte de los españoles "que se figuraban tener la puerta abierta para hacerse alternativamente españoles y mexicanos, jugando y especulando con ambas nacionalidades según conviniera a sus intereses". Sin embargo, las recomendaciones enviadas a Lozano desde Madrid iban en el sentido de estar en estrecha comunicación y consulta con el gobierno mexicano para buscar su anuencia en casos específicos. Pero ese procedimiento no había resultado eficaz del todo:

Posteriormente muchos de los españoles de que se trata habían regularizado por decirlo así su doble ciudadanía. Aceptaban por ejemplo un destino de este gobierno, dejaban por consiguiente de inscribirse anualmente en la matrícula, y perdían todo derecho a ser protegidos por esta legación, y aun cuando no se naturalizaban mexicanos se hacían pasar tácitamente por tales. Acontecía una circunstancia política o de cualquier otro género que les fuera perjudicial, entonces se presentaban a solicitar su carta de seguridad y volvían a ser españoles; sin que esto se

${ }^{34}$ Minuta. Al encargado de Negocios de S.M., en México, Madrid, 28 de diciembre de 1847, AHN, sección: Estado, legajo 5867, número 231. 
pudiera impedir, porque, como dejo dicho, el convenio no tiene tiempo limitado. ${ }^{35}$

En el lado mexicano, José María Lafragua, al abordar los problemas de la deuda externa mexicana, hizo también un balance respecto a los convenios sobre nacionalidad de 1842 y 1847, así como a otros acuerdos de esa época entre España y México, que nos revela una sensación de despojo y desaliento:

De todos estos antecedentes nacen consideraciones gravísimas, que prueban los sacrificios que México ha hecho por su antigua metrópoli. En 1841 reconoció un crédito que no tenía obligación de pagar. En 1842 consintió en que los españoles recobrasen su nacionalidad, concesión inmensamente perjudicial, que ha abierto ancha puerta a los abusos cometidos después y es sin duda el origen de los males que hoy lamentamos. En 1847 convino en reiterar esa fatal decisión, que entonces fue además altamente dolorosa, porque envolvía una verdadera ingratitud de parte de los hombres que habiendo hecho sus fortunas en el país, le abandonaban en la hora del peligro, y después de haber recibido todo género de bienes de aquel pueblo, cuando era próspero y feliz, le volvían la espalda en la desgracia y renegaban de su bandera cuando defendía palmo a palmo el territorio nacional. ${ }^{36}$

\section{La elección de la nacionalidad}

¿Qué tanto permearon a la población los cambios en la legislación relativa a la nacionalidad? ¿Realmente fueron aprovechadas las oportunidades que se presentaban para mudar de nacionalidad? Si ése fue el caso, además de las razones ya expuestas, ¿había otras más para

${ }^{35}$ Ramón Lozano, ministro plenipotenciario de S.M., al primer secretario del Despacho de Estado, México, 26 de mayo de 1855, AMAE, TR 441, despacho número 138.

${ }^{36}$ José María Lafragua, Memorandum de los negocios pendientes entre México y España presentado al Excmo. Sr. Ministro de Estado por el representante de la República el día 28 de julio de 1857, 1857, Poissy, Tipografía de Arbieu, p. 103-4. 
preferir la nacionalidad española a la mexicana? Una fuente que nos permite acercarnos a algunas posibles respuestas es la que se refiere a las 'cartas de seguridad'.

Las entradas y salidas de México fueron controladas mediante la expedición de pasaportes, pero los extranjeros que decidían permanecer en el país debían tramitar una 'carta de seguridad', documento que los acreditaba como tales y les permitía desplazarse libremente por el territorio mexicano, con la protección de las leyes y los derechos civiles que éstas garantizaban a los mexicanos. Las cartas debían tramitarse a través de la legación del extranjero en cuestión, si la había, o directamente con las autoridades mexicanas; tenían vigencia de un año, tras el cual debían renovarse. El costo para su expedición o renovación fue al principio de un peso, pero esa cantidad se incrementó hasta llegar a cuatro, aunque también podían ser "gratis, en los casos que el gobierno califique haber mérito para ellos". ${ }^{37}$ El incumplimiento de esa obligación se penaba con una multa de 20 pesos o diez días de prisión. ${ }^{38}$ Sin embargo, la abundante legislación al respecto constituye un indicio del notable subregistro hasta el final de su vigencia, estipulado en la constitución de 1857. Así, la expedición de las cartas de seguridad ponía en contacto a los extranjeros, los representantes de sus gobiernos y a las autoridades mexicanas, locales y nacionales. En la práctica cotidiana, esto daría lugar a negociaciones, acuerdos y desencuentros entre las partes involucradas, en torno al cumplimiento de esa norma.

${ }^{37}$ La exención del pago era para los 'pobres de solemnidad', pero en el caso de los españoles esta salvedad dio lugar a prácticas de corrupción cuando en 1853 el enviado español, Marqués de la Rivera, tramitó ante la Secretaría de Relaciones Exteriores un buen número de cartas sin costo, pero que los vicecónsules no habían solicitado como tales y cuyo pago, en cambio, sí habían cubierto.

38 "Reglamento sobre pasaportes", 1o., de mayo de 1828, en Basilio José Arrillaga, Recopilación de leyes, decretos, bandos, reglamentos, circulares y providencias de los Supremos Poderes y otras autoridades de la República Mexicana, formada de orden del Supremo Gobierno por (...), 1828, México, Imp. De José M. Lara, v. 1, 1828, p. 108; también en Dublán y Lozano, op. cit., t. II, pp. 69-72. "Ley. Derechos de pasaporte para entrar o salir de la República, de cartas de seguridad y certificaciones de firmas", 12 de octubre de 1830 , en ibid., p. 291. 
Respecto a los españoles y en caso de residir fuera de la capital, los interesados recurrían al consulado o viceconsulado más cercano para solicitar sus cartas y el funcionario español, a su vez, lo hacía al consulado general y éste a la secretaría de Relaciones Exteriores. Una vez obtenido, el documento seguía el mismo camino en sentido inverso. Así, a la suma de \$2.00 que cobraban las autoridades mexicanas se agregaba la comisión del consulado general y el costo del envío por correo, lo que elevaba su monto a $\$ 3.50$. Tanto en el consulado o viceconsulado del interior de la república como en el consulado general debían quedar asentados los datos de cada 'súbdito' español formando una 'matrícula' que servía de guía para determinar, llegado el caso, si un individuo era considerado español y se hacía acreedor a la protección de la legación. Los documentos básicos con los que el interesado podía probar su origen y/o residencia eran la fe de bautismo o el pasaporte de entrada al país, pero la condición de extranjero, en el marco legal mexicano, sólo se acreditaba con la carta de seguridad. En ese sentido, si bien era la Secretaría de Relaciones Exteriores la que determinaba en última instancia conceder o no ese documento, el trámite estaba prácticamente asegurado si se hacía a través del consulado general (en su caso, previa solicitud de los vicecónsules y cónsules del interior).

Con mucha frecuencia, los cónsules y vicecónsules se quejaban de que los españoles acudían directamente a las autoridades locales mexicanas para ahorrarse así la cuota del consulado. Esa práctica mermaba los ingresos de este último, dejaba incompletas las matrículas y fue causa de constantes disgustos por parte de los cónsules generales, como podemos apreciar en la respuesta de Ramón Lozano al vicecónsul en Chihuahua:

Como Usted dice muy bien, solicitando esos súbditos españoles sus cartas de seguridad por conducto del gobierno del Departamento se ahorran doce reales de los derechos consulares; parece que encuentran demasiado caro este tributo y que, con tal de no pagarlo, prefieren salvar el conducto de ese viceconsulado y acudir a un gobierno extranjero para que los califique de españoles. Es un patriotismo y una economía 
bastante curiosos. Puede Usted decirles de mi parte que para el año que viene se les darán gratis los derechos consulares si tanto les molesta esta pequeña contribución. ${ }^{39}$

Desde 1842, una petición del cónsul general transmitida por Pedro Pascual de Oliver al ministro de Relaciones Exteriores, José Ma. Bocanegra, iba en el sentido de "que en lo sucesivo no se librase a los súbditos españoles carta de seguridad sino en virtud del certificado del consulado general de España" ${ }^{40}$ La solicitud fue concedida pero no impidió que muchos españoles siguiesen tramitando sus cartas de seguridad directamente ante las autoridades locales mexicanas sin atender la advertencia, difundida a través de los vicecónsules, de que la legación no respaldaría las quejas de, ni brindaría protección a los españoles que no tramitasen sus cartas por medio de la legación. Esto resulta curioso si tomamos en cuenta, por una parte, la instrucción dada al ministro Bermúdez de Castro, a propósito del convenio de $1847,{ }^{41}$ en el sentido de que "toda la población mexicana que sea de origen español está en el caso de ser admitida bajo el pabellón español, (...) porque todos ellos , o han sido españoles, cuando aquel estado era español, o son hijos de los que fueron españoles", y por la otra, la respuesta del enviado español al vicecónsul en Oaxaca consultándole:

si los Españoles que no renueven algún año su carta de seguridad, pierden por este hecho la ciudadanía de su nación, le contesto diciéndole, que la ciudadanía no se pierde sino en los casos y por las causas que señala la Constitución de la Monarquía: que el sacar anualmente carta de seguridad es una disposición prevenida por ley de esta República, a la que deben someterse todos los extranjeros que eligen (establecer) en ella su residencia; que el Gobierno Mexicano se halla en el derecho de exigir el cumplimiento de dicha ley y que no considera como extranjeros,

${ }^{39}$ Minuta. (Ramón Lozano y Armenta, cónsul general y ministro...) al vicecónsul (...) en Chihuahua, México, 20 de febrero de 1855, AGA, (10) 60 s. 54/10 194.

${ }^{40}$ Minuta núm. 97. (Pedro Pascual de Oliver) a José Ma. de Bocanegra, ministro de Relaciones Exteriores, México, 2 de septiembre de 1842, AGA, (10) 61 s. legajo 39, exp. 2.

${ }^{41}$ Vid. supra. 
para el goce de la protección de sus legaciones a los que se niegan a cumplir con ella. ${ }^{42}$

Es decir que, de acuerdo con este criterio amplio, para las autoridades hispanas los españoles en México eran todos los que tenían ese origen, y nunca habían dejado de serlo. Pero también, los que tramitaban su carta de seguridad a través de la legación, pagando su respectiva cuota, aseguraban de esta forma la protección brindada por esa instancia.

Por otro lado, la evidencia del trámite ininterrumpido de las cartas de seguridad entre 1843 y 1857 representa un indicio de las necesarias definición y elección de la nacionalidad, mexicana o española, con la que se desenvolvería cada individuo por el país, aun cuando al hacerlo optase por alternarlas, año con año, y en ese sentido manejar deliberadamente esa posibilidad. ${ }^{43}$ Asimismo, incluso cuando el subregistro fuese algo común, es posible advertir un aumento en el número de las solicitudes de cartas de seguridad desde el interior de la república $\mathrm{y}$, por lo tanto, de los matriculados en general, a partir sobre todo de 1847, año del segundo convenio (cuadro 1). Por ejemplo, los españoles matriculados en el consulado general en 1843 fueron 1,803, mientras que para 1852 la cifra ascendió a 3,121. Si bien podríamos pensar que el aumento en el registro se debió a la llegada de más españoles al país, el hecho de que en las solicitudes consulares encontremos alusiones explícitas a ese arreglo en el momento de hacer las peticiones refuerza la idea de que se trataba de individuos ya residentes en México que optaban por cambiar su nacionalidad. También llama la atención el hecho de que, si bien con un notable descenso de matriculados, se hayan realizado registros para los años de 1859 y 1860, es decir, después de que la Constitución de 1857 hubiese anulado la obligación de contar

${ }^{42}$ Minuta. (Del enviado y ministro...) al vicecónsul en Oaxaca, México, 26 de junio de 1850, AGA, (10) 60 s. 54/ 10179.

${ }^{43}$ Las solicitudes de cartas de seguridad de los cónsules y vicecónsules españoles en México pueden consultarse en AGA (10) 60, s. 54/10191, 54/10192, 54/10179 y 54/10186; AGA, (10) 61, s. Legajos 7, 31 y 39; AGA, (10) 61, s. Legajo 39, exp. 2. 
con cartas de seguridad. Lo anterior puede explicarse tal vez en función de la incertidumbre derivada de la guerra civil de esos años, y en la decisión, como una medida de protección, de seguir levantando las matrículas hasta no ver resuelta esa situación.

\section{Cuadro 1}

Españoles matriculados en los consulados y viceconsulados en México

$\begin{array}{cc}\text { Años } & \text { Españoles matriculados en México } \\ 1840 & 1,324 \\ 1841 & 1,576 \\ 1842 & 1,401 \\ 1843 & 1,803 \\ 1852 & 3,121 \\ 1854 & 3,554 \\ 1855 & 3,100 \\ 1856 & 3,237 \\ 1859 & 1,175 \\ 1860 & 1,397\end{array}$

Fuente: Índices de matrícula, AGA, (10), 5, s., libros 3453, 3455, 3456, 3471, 3472, 3559 y 3563.

Pero, ¿qué otras circunstancias llevaban a preferir la nacionalidad española a la mexicana? Para un pequeño grupo de comerciantes y comerciantes-agiotistas evidentemente el recurso de contar con el respaldo y protección de la legación y el gobierno españoles para la realización de sus transacciones económicas y eventuales reclamaciones. ${ }^{44}$ Para el resto de la población, y de acuerdo con las versiones de los

${ }^{44}$ Así lo han señalado Antonia Pi-Suñer, Agustín Sánchez Andrés y Rosa María Meyer en sus trabajos ya citados. 
funcionarios españoles, la posibilidad de evadir 'cargas concejiles' ${ }^{\text {'5 }}$ o los 'sorteos' (para las levas del ejército), o bien evitar 'sacrificios pecuniarios y servicios forzosos'. Así, podía constituir una medida de protección para evitar disposiciones judiciales adversas, como en el caso de tres particulares: Victoriano Franco Martínez, por cierto familiar del general Santa Anna, al no cumplir un contrato comercial; Cipriano de las Cajigas, periodista e involucrado en cuestiones políticas, y José Ghilardi, militar 'confinado en Querétaro'. Hay que destacar que, en estos tres casos, fue fundamental la intercesión del enviado español ante el secretario de Relaciones, así como la de algunos de sus connacionales con los representantes de su país para obtener resultados favorables. ${ }^{46}$

Por otro lado, resulta significativo el escaso número de solicitudes de cartas de seguridad denegadas o que, por su retraso, habían dado lugar a las multas correspondientes. Incluso entonces entraba en juego la capacidad de negociación de los cónsules generales o de los ministros con las autoridades mexicanas, como un último recurso para obtener las cartas en cuestión, eliminar las multas o lograr la aplicación discrecional de la ley, como en el caso de la solicitud del religioso fray Emeterio Sáenz de Heredia:

Ahora diré a usted que han sido inútiles mis gestiones para conseguirlo. Existe, como Usted sabía, una ley que prohíbe la entrada en la

${ }^{45}$ Uno de los testimonios en este sentido es el siguiente: “Algunos españoles que están avecindados en esta Ciudad (Tabasco) y pueblos del Departamento con más de 20 años de residencia, quienes poseen fincas rústicas y urbanas y son casados con mexicanas, me han suplicado consulte a V.E., si podrán renunciar y pedir la carta de seguridad como súbditos de España, cuya mira es la de evitar se les ocupe en cargos concejiles con los que corren riesgo sus propiedades en los cambios de gobierno, más que si fuesen hijos del país." Pablo Sastré y Mazas al ministro Ángel Calderón, San Juan Bautista, 14 de junio de 1840, AGA, (10) 61, s. legajo 7.

${ }^{46}$ El enviado Ramón Lozano informó que en el caso de don Cipriano de las Cajigas, "varios compatriotas suyos respetables intercedieron en su favor, y al fin me decidí a dar algunos pasos confidenciales cerca de este gobierno"; respecto a don José Ghilardi: "Otros españoles vinieron a suplicarme que intercediera con este gobierno para que se le levantara el confinamiento y se le permitiera regresar a esta capital." Ramón Lozano al Primer Secretario del Despacho de Estado, México, 26 de mayo de 1855, AMAE, TR 441, despacho número 481. 
República a individuos de comunidades religiosas, procedentes de países extranjeros. El gobierno mexicano, más o menos tolerante en este punto según las diferentes circunstancias y las personas que han dirigido la administración, se han reservado siempre el derecho de cumplir estrictamente aquella ley si así lo consideraba necesario. A alguno que otro de aquellos individuos que han venido a esta capital para gestionar por asuntos de intereses de su orden o privados suyos les he conseguido, una vez que han manifestado y probado el objeto de su venida, su respectiva carta de seguridad, pero ha sido una muestra de deferencia personal que no puedo ni debo pedir con demasiada frecuencia. Tratándose ahora de un religioso ausente de España hace nueve años, que ha vivido en países extranjeros todo este tiempo, ignorando yo con qué objeto viene a esta república, si bien solicité amistosamente del gobierno su carta de seguridad, no he podido extrañar que en esta vez se haya negado a concedérsela. Todo lo que me ha prometido es que no le obligará a salir y que tolerará su permanencia temporal en este país. ${ }^{47}$

Hubo pocas solicitudes rechazadas porque no se cumplía alguno de los requisitos exigidos por las leyes o los convenios sobre nacionalidad, así como la imposición de multas por solicitudes tardías, algunas de las cuales fueron finalmente anuladas gracias a la gestión de los enviados españoles. Pero se trató en cualesquiera de los casos, de una cantidad insignificante en relación con el total de las solicitudes y no mayor de treinta, lo cual nos permite suponer el hecho de que los representantes españoles asentados en la capital facilitaron al máximo a sus compatriotas la obtención de las cartas de seguridad, intercediendo por ellos ante las autoridades mexicanas cuando era necesario.

\section{Conclusiones}

La definición de la nacionalidad en México entre 1821 y 1857 no fue un asunto ambiguo en términos de la legislación. En el caso de los

\footnotetext{
${ }^{47}$ Minuta. (Ramón Lozano) a Francisco Martínez, (vicecónsul en Guadalajara), México, 16 de septiembre de 1848, AGA, 10 (61) s. legajo 39, exp. 2.
} 
españoles peninsulares, las principales leyes constitucionales establecieron que los que se encontraban en el país en el momento de la consumación de la independencia (1821) eran mexicanos, mientras que los que llegaran después de esa fecha eran considerados extranjeros. La exigencia de obtener o renovar anualmente una 'carta de seguridad' para acreditar ese estatus es una prueba de lo anterior. Por cierto, falta todavía por investigar cuántos de entre los 'españoles' expulsados entre 1827 y 1833 eran ya en realidad mexicanos, por las propias leyes de este país. En ese caso, estaríamos ante el predominio de un criterio étnico -y político por el contexto en que se dieron las leyes de expulsión de los españoles ${ }^{48}$ - sobre uno legal.

Sin embargo, el retraso en el reconocimiento español del nuevo Estado, así como las pugnas políticas en sus primeros años afectaron la permanencia en México de los españoles de origen, incluso de aquellos que habían pasado a ser mexicanos. La llegada del primer ministro plenipotenciario español, a finales de 1839, y la regularización de las relaciones diplomáticas entre ambos gobiernos permitió no sólo un incipiente registro de la presencia española en el país -las cartas de seguridad llevaban al levantamiento de matrículas en los consulados y viceconsulados- sino también abrió el camino para la constante negociación entre las autoridades mexicanas y españolas, con el fin de cambiar las leyes relativas a la nacionalidad, o atenuar su efecto mediante su aplicación discrecional. En ese sentido, tal vez la afinidad cultural en términos del conocimiento de códigos, usos y costumbres mexicanos fue un recurso favorable a los diplomáticos españoles, en relación con los de otras potencias extranjeras. Así, se trató con frecuencia del arte de aprovechar a la persona indicada en la circunstancia oportuna, que en este caso fue el general Antonio López de Santa Anna.

El convenio de 1847 proporcionó a los españoles de origen la posibilidad de moverse entre una y otra nacionalidad, según sus intereses.

${ }^{48}$ Véase al respecto el trabajo de Érika Pani, "De coyotes y gallinas: Hispanidad, identidad nacional y comunidad política durante la expulsión de españoles", en Revista de Indias, LXIII: 228 (mayo-agosto, 2003), p. 355-73. 
Pero la constante inestabilidad del país en las primeras décadas de su vida independiente, las agresiones internacionales - como la invasión norteamericana de 1846-1848- también llevaron a otra parte de la población a ver en el cambio de la nacionalidad una vía para la protección de sus bienes y personas, o sencillamente para eludir disposiciones legales de los gobiernos mexicanos. La diferencia radicaba en contar con el respaldo de una potencia extranjera, mediante las acciones diplomáticas de su legación, para defender intereses privados, sin que ello fuese, sin embargo, garantía total de éxito. ${ }^{49}$ Por otro lado, resulta difícil establecer si la decisión de mudar legalmente de nacionalidad tenía alguna relación con el sentido de arraigo o identidad de cada uno hacia su país de origen y con la forma de desenvolverse en su vida cotidiana, en términos de costumbres, expectativas, etc.

En suma, a la par que la comunidad española en México iba recuperando y afianzando su lugar privilegiado en la vida económica mexicana -las propias expresiones de antihispanismo ${ }^{50}$ de la época podrían ser leídas como un indicio de ello- el país en su conjunto no daba señales de superar sus problemas de inestabilidad política, insolvencia, desigualdad y caos sociales, por lo cual la disyuntiva acerca de la elección de la nacionalidad en realidad parecía darse en términos de: ser o no ser.... mexicano en México.

\section{Archivos:}

AHN Archivo Histórico Nacional (Madrid, España). AGA Archivo General de la Administración Española (Alcalá de Henares, España) AMAE Archivo del Ministerio de Asuntos Exteriores (Madrid, España).

AHSRE Archivo Histórico Genaro Estrada de la Secretaría de Relaciones Exteriores (México, D. F.).

49 Tal como lo ha mostrado Rosa María Meyer, en op. cit., 2003, p. 77-91.

${ }^{50}$ En este sentido, véase el trabajo de Romana Falcón, Las rasgaduras de las descolonización. Españoles y mexicanos a mediados del siglo XIX, 1996, México, Centro de Estudios Históricos, El Colegio de México. 
La reproducción total o parcial de este artículo se podrá hacer si el ITAM otorga la autorización previamente por escrito. 